\title{
Letter
}

\section{Photogeneration and Thermal Generation of Pentacene from Soluble Precursors for OTFT Applications}

Ta-Hsien Chuang, Hsing-Hung Hsieh, Chang-Ken Chen, Chung-Chih Wu, Chao-Chen Lin, Pi-Tai Chou, Ting-Han Chao, and Tahsin J. Chow

Org. Lett., 2008, 10 (13), 2869-2872• DOI: 10.1021/ol8010419 • Publication Date (Web): 30 May 2008

Downloaded from http://pubs.acs.org on February 18, 2009

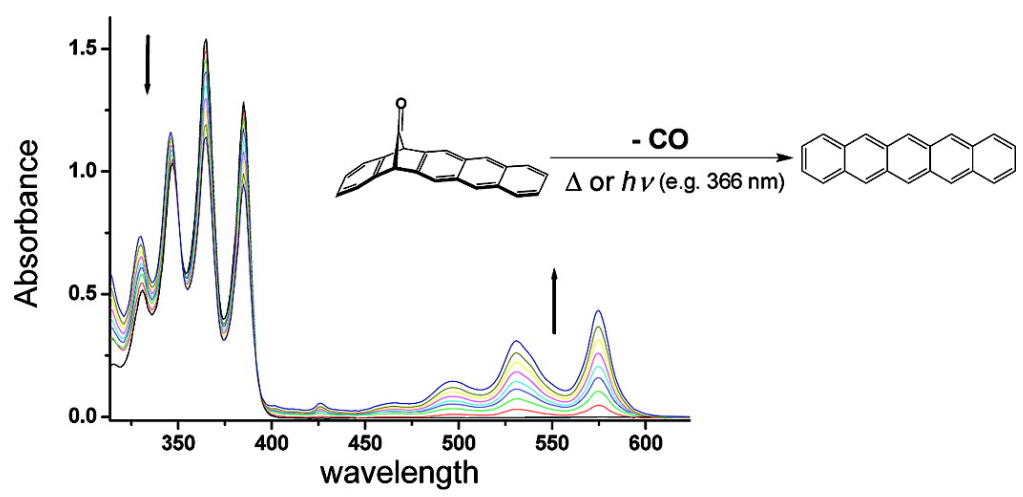

\section{More About This Article}

Additional resources and features associated with this article are available within the HTML version:

- $\quad$ Supporting Information

- Access to high resolution figures

- $\quad$ Links to articles and content related to this article

- Copyright permission to reproduce figures and/or text from this article

\section{View the Full Text HTML}




\section{Photogeneration and Thermal Generation of Pentacene from Soluble Precursors for OTFT Applications}

2008

Vol. 10, No. 13

2869-2872

\section{Ta-Hsien Chuang, ${ }^{\dagger}$ Hsing-Hung Hsieh, ${ }^{\ddagger}$ Chang-Ken Chen, ${ }^{\ddagger}$ Chung-Chih Wu, ${ }^{*, \neq}$ Chao-Chen Lin, ${ }^{\S}$ Pi-Tai Chou, ${ }^{*,}$ Ting-Han Chao, ${ }^{\perp}$ and Tahsin J. Chow ${ }^{*, \dagger}$}

Institute of Chemistry, Academia Sinica, Taipei 115, Taiwan, Department of Electrical Engineering and Graduate Institute of Electronics Engineering, National Taiwan

University, Taipei 106, Taiwan, Department of Chemistry, National Taiwan University,

Taipei 106, Taiwan, and Department of Chemistry, National Taiwan Normal

University, Taipei 106, Taiwan

tjchow@chem.sinica.edu.tw

Received May 6, 2008

\section{ABSTRACT}

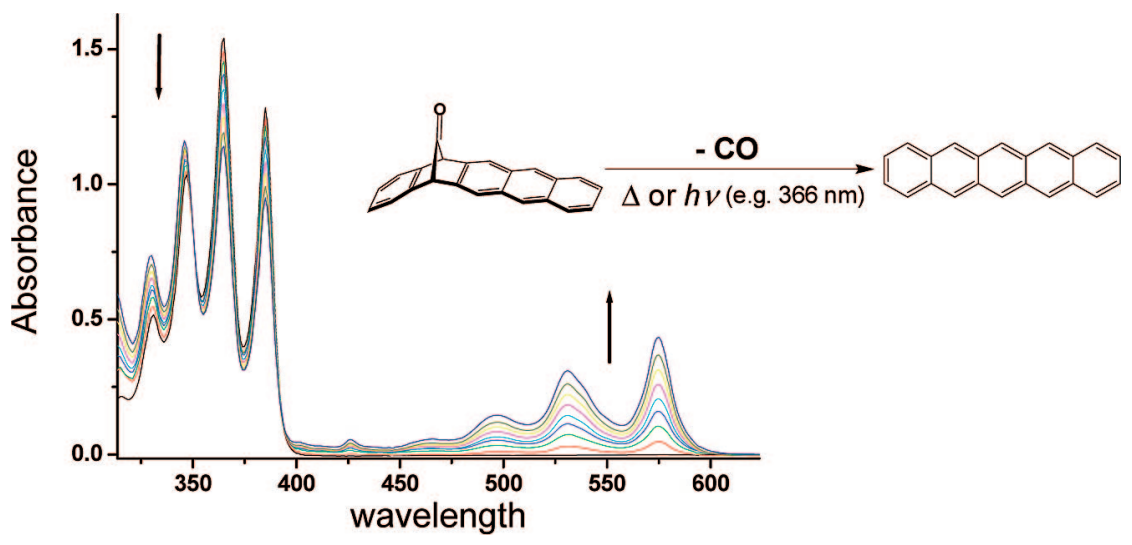

A CO adduct of pentacene with an unsymmetrical structure is synthesized; it is soluble and can be spin-coated into thin films. Pentacene is regenerated in near quantitative yield by either thermal or photoinduced elimination of CO. OTFT devices fabricated by this compound exhibit typical FET characteristics.

Designing electronic devices made of organic materials is currently the subject of intensive interest. The most promising p-type semiconductor for use in organic thin-film transistors (OTFT) is pentacene. ${ }^{1}$ The high charge mobility of pentacene can be attributed to its high degree of crystallinity in the solid state, ${ }^{2}$ yet the same property also renders its low solubility in organic solvents. ${ }^{3}$ It is rather difficult to prepare

$\dagger$ Academia Sinica.

Department of Electrical Engineering, National Taiwan University.

$\S$ Department of Chemistry, National Taiwan University.

${ }^{\perp}$ Department of Chemistry, National Taiwan Normal University.

(1) For recent reviews:(a) Zaumseil, J.; Sirringhaus, H. Chem. Rev. 2007, 107, 1206. (b) Murphy, A. R.; Fréchet, J. M. Chem. Rev. 2007, 107, 1066. thin films of pentacene through solution processes. To circumvent this problem, scientists at Philips ${ }^{4}$ and $\mathrm{IBM}^{5}$ have developed a strategy of designing precursors of pentacene that are soluble in organic solvents and can be used to

(2) Gundlach, D. J.; Lin, Y. Y.; Jackson, T. N.; Nelson, S. F.; Schlom, D. G. IEEE Electron Device Lett. 1997, 18, 87.

(3) Minakata, T.; Natsume, Y. Synth. Met. 2005, 153, 1.

(4) (a) Brown, A. R.; Pomp, A.; de.Leeuw, D. M.; Klaassen, D. B. M.; Havinga, E. E.; Herwig, P.; Müllen, K. J. Appl. Phys. 1996, 79, 2136. (b) Herwig, P. T.; Müllen, K. Adv. Mater. 1999, 11, 480.

(5) (a) Weidkamp, K. P.; Afzali, A.; Tromp, R. M.; Hamers, R. J. J. Am. Chem. Soc. 2004, 126, 12740. (b) Afzali, A.; Dimitrakopoulos, C. D.; Breen, T. J. Am. Chem. Soc. 2002, 124, 8812. (c) Afzali, A.; Kagan, C. R.; Traub, G. P. Synth. Met. 2005, 155, 490 . 
generate pentacene on demand. The structures of these precursors are usually cycloadducts of pentacene itself (acting as a diene) with another small volatile fragment (acting as a dienophile). After a film is produced by spin-coating, pure pentacene can be regenerated upon heating through a retrocyclization reaction.

As most of the cycloreversion processes are activated by thermal energy, photoinduced dissociation is scant. Present technologies for making integrated electronic circuits rely largely on photolithography, by which large areas can be patterned. ${ }^{6}$ There has been only one earlier report on photogeneration of pentacene via a cycloreversion process, yet no corresponding device data have been released. ${ }^{7}$

In this study, we report an unprecedented case of photogeneration of pentacene from both $\mathrm{CO}$-adducts $\mathbf{1}$ and $\mathbf{2}$, and their successful utilization in OTFT devices. Synthesis of the symmetrical compound $\mathbf{1}$ has been reported by us previously. ${ }^{8}$ Pure pentacene was generated by $\mathrm{CO}$ expulsion at $150{ }^{\circ} \mathrm{C}$, and the device made with it exhibited typical FET characteristics. Recently we have discovered that the $\mathrm{CO}$ expulsion can also be achieved effectively through photolysis. To increase the efficiency of photolysis, we have further designed its isomer $\mathbf{2}$ with an unsymmetrical structure in which the position of the $\mathrm{CO}$ bridge is shifted off the central aromatic ring. The absorptivity of compound $\mathbf{2}$ is expected to be higher than that of $\mathbf{1}$ due to its noncentral symmetrical geometry. The sizes of the major chromophores in these two compounds are different, i.e., a naphthalene in $\mathbf{1} \mathrm{cf}$. an anthracene in 2. The HOMO-LUMO band gap of the anthracene chromophore is narrower than that of naphthalene; therefore the low-lying absorption bands of 2 are expected to be red-shifted. As a result, the activation energy required for photoelimination is reduced. Comparing the possible reactivity of $\mathbf{1}$ and $\mathbf{2}$, the latter should have the advantages of lower photodissociation energy along with higher quantum efficiency. Here we describe the preparation and physical properties of $\mathbf{2}$, as well as the preformance of OTFT devices made with it through either a thermal or a photochemical process

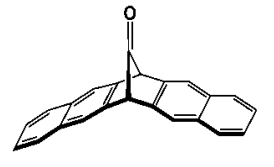

1

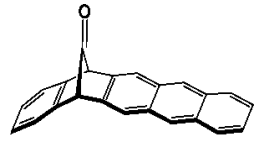

2
The synthesis (Scheme 1) was started from a $[4+2]$ cycloaddition reaction of the furan derivative $\mathbf{3}$ with the benzonorbornadiene derivative $\mathbf{4}$, which afforded the adduct

(6) (a) Afzali, A.; Dimitrakopoulos, C. D.; Graham, T. O. Adv. Mater. 2003, 15, 2066. (b) Weidkamp, K. P.; Afzali, A.; Tromp, R. M.; Hamers, R. J. J. Am. Chem. Soc. 2004, 126, 12740.

(7) (a) Uno, H.; Yamashita, Y.; Kikuchi, M.; Watanabe, H.; Yamada, H.; Okujima, T.; Ogawa, T.; Ono, N. Tetrahedron Lett. 2005, 46, 1981. (b) Yamada, H.; Yamashita, Y.; Kikuchi, M.; Watanabe, H.; Okujima, T.; Ogawa, T.; Ohara, K.; Ono, N. Chem. Eur. J. 2005, 11, 6212.

(8) (a) Chen, K. Y.; Hsieh, H. H.; Wu, C. C.; Hwang, J. J.; Chow, T. J. Chem. Commun. 2007, 1065. (b) Lai, C. H.; Li, E. Y.; Chen, K. Y.; Chow, T. J.; Chou, P. T. J. Chem. Theory Comput. 2006, 2, 1078.
Scheme 1. Synthetic Scheme toward Compound 2

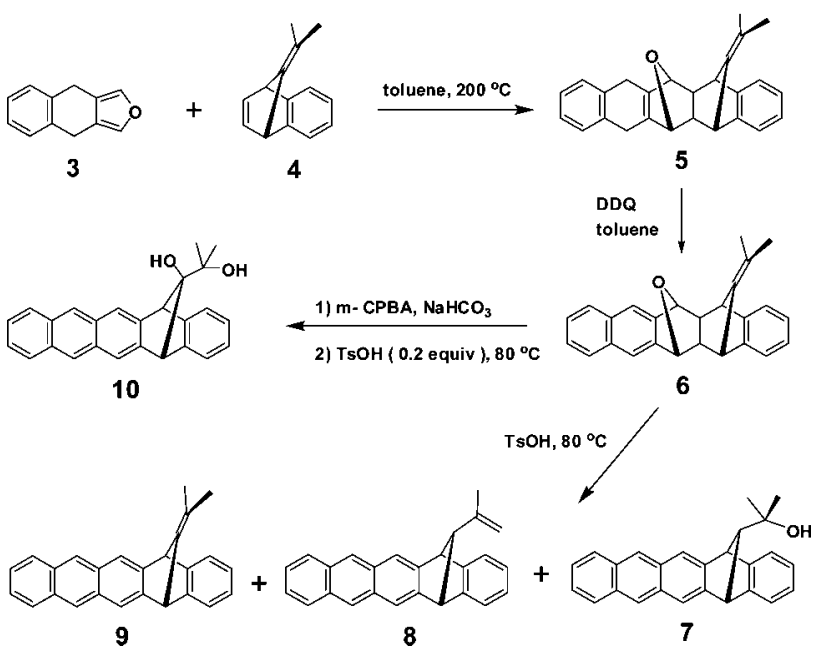

5 in $72 \%$ yield. ${ }^{9}$ The $C_{s}$ symmetrical geometry of $\mathbf{5}$ was verified by the presence of 14 absorption signals in the ${ }^{13} \mathrm{C}$ NMR spectrum. In the ${ }^{1} \mathrm{H}$ NMR spectrum the two methylene hydrogens were shown as two separate doublets, at $\delta 3.27$ and 3.57 , with a large coupling constant $(20 \mathrm{~Hz})$. Aromatization of the fourth ring of $\mathbf{5}$ was done by oxidation with dicyanodichloroquinone (DDQ), whereby 6 was obtained in a quantitative yield. The three types of methinyl hydrogens appeared as three singlets at $\delta$ 1.99, 3.93, and 5.33, respectively, in the ${ }^{1} \mathrm{H}$ NMR spectrum. Further dehydration/ aromatization under catalysis with toluenesulfonic acid resulted in a complicated mixture of compounds $\mathbf{7 , 8}$, and 9, with a total yield of $75 \%$. Their relative ratio depended on the concentration of acid as well as the time of reaction. The quaternary carbon of 7, to which the hydroxyl group was attached, was shown as a singlet signal at $\delta 71.5$ in the ${ }^{13} \mathrm{C}$ NMR spectrum. Compounds 8 and 9 were believed to be secondary products derived from 7 . The optimized yield of $\mathbf{9}$, as a potential precursor of $\mathbf{2}$, was less than $5 \%$. To improve the yield of the desired product, compound $\mathbf{6}$ was first treated with $m$-CPBA to form an epoxide, followed by an acid-catalyzed rearrangement. The diol $\mathbf{1 0}$ was obtained in $74 \%$ yield as the major product. The presence of a 1,2diol was evidenced by a strong absorption band at 3450-3550 $\mathrm{cm}^{-1}$ in the IR spectrum and the two quaternary carbon signals at $\delta 74.3$ and 105.5 in the ${ }^{13} \mathrm{C}$ NMR. Oxidation of 10 by $\mathrm{PhI}(\mathrm{OAc})_{2}$ cleaved the $\mathrm{C}-\mathrm{C}$ bond, giving the target ketone $\mathbf{2}$ in $76 \%$ yield. The carbonyl group shows a strong absorption at $1782 \mathrm{~cm}^{-1}$ in IR, and a low field peak at $\delta$ 192.2 in ${ }^{13} \mathrm{C}$ NMR. The optimized overall yield from $(3+$ 4) to 2 was $40 \%$.

Ketone $\mathbf{2}$ was made from 9 through ozonolysis in a mixed solvent $\left(\mathrm{CH}_{2} \mathrm{Cl}_{2}: \mathrm{MeOH}=2: 1\right)$ at $-35^{\circ} \mathrm{C}$, followed by a reduction of the ozonide intermediate with dimethyl sulfide. However, due to the low yield of $\mathbf{9}$, this method was not adopted for the production of 2 .

(9) (a) Garratt, P. J.; Neoh, S. B. J. Org. Chem. 1979, 44, 2667. (b) Lombardo, L.; Wege, D.; Wilkinson, S. P. Aust. J. Chem. 1974, 27, 143. 
The UV absorption spectrum of $\mathbf{2}$ is quite different from that of 1 (Figure 1). A strong $\pi-\pi^{*}$ transition $\left({ }^{1} A \rightarrow{ }^{1} B\right)$ of

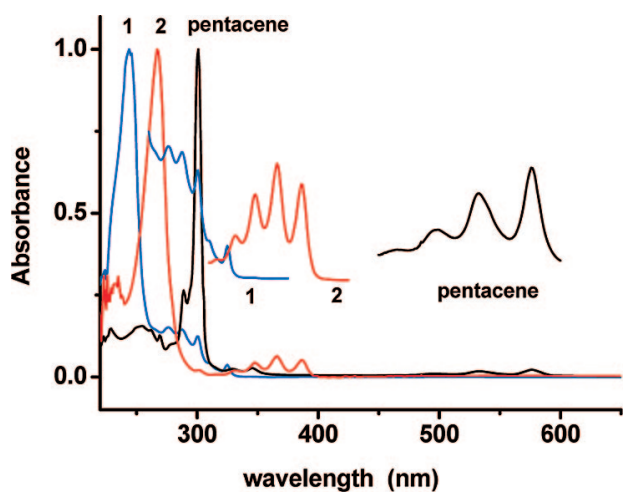

Figure 1. UV absorptions of compounds 1 (blue), 2 (red), and the thermally generated pentacene (black). The long-wavelength bands are magnified in the center of the graph.

2 gives a strong peak at $268 \mathrm{~nm}$, which is longer than the corresponding absorption of $\mathbf{1}$ at $244 \mathrm{~nm}$. This band is known to be longitudal polarized and is red-shifted with the size of polyacenes. ${ }^{10}$ The weaker ${ }^{1} A \rightarrow{ }^{1} L_{\mathrm{a}}$ transition of 2 appears at $387 \mathrm{~nm}$, which is also significantly red-shifted to the corresponding one of $\mathbf{1}$ at $300 \mathrm{~nm}$. The latter band is partly overlapped with the ${ }^{1} A \rightarrow{ }^{1} L_{\mathrm{b}}$ transition at $324 \mathrm{~nm}$.

Compound 2 was stable at ambient temperature yet began to turn purplish at $128{ }^{\circ} \mathrm{C}$. The fragmentation temperature was lower than that of $\mathbf{1}$, which decomposed at $150{ }^{\circ} \mathrm{C}$. A $10 \%$ weight loss, as indicated by a thermogravimetric curve (Figure 2), corresponded to the weight ratio of a $\mathrm{CO}$ unit.

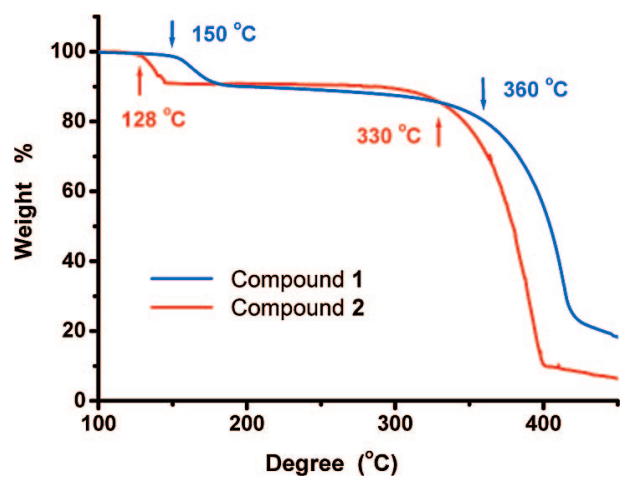

Figure 2. Comparison of TGA profiles of compounds $\mathbf{1}$ (blue) and $\mathbf{2}$ (red) at $10 \mathrm{deg} / \mathrm{min}$ heating rate. The $\mathrm{CO}$ extrusion reaction of $\mathbf{2}$ started at $128{ }^{\circ} \mathrm{C}$, and the resulting pentacene was stable to 300 ${ }^{\circ} \mathrm{C}$.

The pentacene thus produced was stable up to $300{ }^{\circ} \mathrm{C}$. Its UV spectrum (Figure 1) showed a strong peak at $300 \mathrm{~nm}$ $\left({ }^{1} B\right.$ band for a $\pi-\pi^{*}$ transition), along with a characteristic long-wavelength absorption at $576 \mathrm{~nm}\left({ }^{1} L_{\mathrm{a}}\right.$ band). The spectrum was identical with that obtained from authentic pentacene, indicating a very high yield in the thermal transformation. In the IR region, the strong absorption of the carbonyl group at $1782 \mathrm{~cm}^{-1}$ disappeared completely after heating. The solubility of $\mathbf{2}$ was found to be similar to that of 1, i.e., $\sim 0.7 \mathrm{mg} / \mathrm{mL}$ in either DCM or THF. However, we have found an effective way to increase the solubility by mixing $\mathbf{1}$ and $\mathbf{2}$ together. The solubility of an equal molar mixture of $\mathbf{1}$ and $\mathbf{2}$ was double that of the individual compounds, e.g. $\sim 1.5 \mathrm{mg} / \mathrm{mL}$ in DCM. Such a mixture can be used quite suitably for the fabrication of OTFT devices.

Upon UV irradiation at the absorption peak of $\sim 366 \mathrm{~nm}$ in degassed THF at room temperature, compound 2 turned gradually from colorless to purplish. As shown in Figure 3,

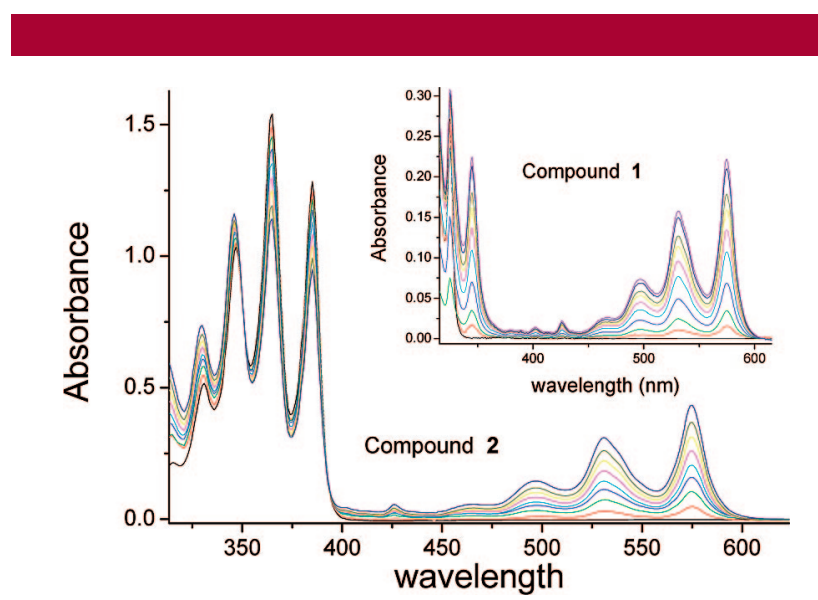

Figure 3. Absorption spectra of $\mathbf{2}$ in degassed THF obtained with different exposure times, 0 to $40 \mathrm{~s}$, with each increment of $5 \mathrm{~s}\left(\lambda_{e x}\right.$ $\approx 366 \mathrm{~nm}$ ). Inset: 1 in degassed THF excited at $310 \mathrm{~nm}$ as a function of exposure times of 0 to $40 \mathrm{~s}$, with each increment of $5 \mathrm{~s}$.

a new absorption band with a peak wavelength around 575 $\mathrm{nm}$ increased along with the time of exposure. An isosbestic point was observed at $\sim 395 \mathrm{~nm}$ throughout the photolysis, indicating the existence of only two compounds in the solution, i.e., the reactant $\mathbf{2}$ and the product. Since the spectral feature of the new band, including the vibronic progression and the associated peak wavelengths, was identical with that of pentacene (cf. Figures 1 and 3), the $\mathrm{CO}$ expulsion from 2 upon UV excitation to form pentacene was well justified. Note that the UV photolysis had to be performed free from $\mathrm{O}_{2}$. Under aeration, $\mathrm{O}_{2}$-trapped adducts were obtained, as indicated by the appearance of a broad, diffusive absorption band at $<400 \mathrm{~nm}$ upon photolysis (not shown here). ${ }^{7}$

The yield of pentacene as photoproduct was further analyzed in a more quantitative manner. In a prototypical experiment, after using a $10 \mathrm{~mW} / \mathrm{cm}^{2} 385 \mathrm{~nm} \mathrm{Nd:YAG}$ pumped $\mathrm{Ti}^{3+}:$ Sapphire laser (LOTIS TII, LT-2211) to illuminate the $3 \mathrm{~mL}$ degassed solution containing compound $2\left(\sim 1.2 \times 10^{-4} \mathrm{M}\right.$ in THF) under stirring for $40 \mathrm{~s}$, it was observed that the absorbance at $575 \mathrm{~nm}$ increased from near zero to $\sim 0.43$, corresponding to an increase of $\sim 4.3 \times 10^{-5}$

(10) Jaffé, H. H.; Orchin, M. O. Theory and Application of Ultraviolet Spectroscopy; John Wiley and Sons, Inc.: New York, 1962. 
$\mathrm{M}$ of pentacene. By taking the ratio of the number of pentacene being produced versus the number of photons being absorbed by 2 , the yield of pentacene production was then calculated to be $16.2( \pm 1.0) \%$. As depicted in the inset of Figure 3, we had also discovered that compound $\mathbf{1}$ underwent a similar photoinduced reaction when irradiated at $310 \mathrm{~nm}$ in degassed THF. ${ }^{7}$ On the basis of a similar photolysis protocol, the yield of pentacene from 1 was estimated to be $12.6( \pm 0.6) \%$.

An OTFT application based on 2 was first investigated by using the well-established thermolysis protocol. In this approach, OTFT devices were fabricated by using a heavily $\mathrm{n}$-doped $\mathrm{Si}$ wafer as the substrate and the gate, and thermally grown $\mathrm{SiO}_{2}$ of $2000 \AA$ as a gate insulator. On top of the $\mathrm{SiO}_{2}$, gold was deposited lithographically to $30 \mathrm{~nm}$ as the source and drain electrodes. Compound 2 was spin-coated repeatedly over the structure to form a thin film, which was then heated to produce pentacene. The output characteristics of a device with a channel width of $20 \mathrm{~cm}$ and a length of $10 \mu \mathrm{m}$ exhibited typical FET characteristics. The OTFT operated in the p-type enhancement mode and exhibited a saturation behavior. Plots of drain current $\left(I_{\mathrm{D}}\right)$ versus drainsource voltage $\left(V_{\mathrm{DS}}\right)$ at various gate voltages $\left(V_{\mathrm{GS}}\right)$ are shown in Figure 4a. The corresponding transfer characteristics, i.e., $\log \left(I_{\mathrm{D}}\right)$ vs $V_{\mathrm{GS}}$ for $V_{\mathrm{DS}}=-80 \mathrm{~V}$, and $I_{\mathrm{D}}^{1 / 2}$ vs $V_{\mathrm{GS}}$ in the saturation mode, are shown in Figure $4 \mathrm{~b}$. The OTFT exhibited an on/off current ratio of about $1.48 \times 10^{4}$, and the apparent field-effect mobility was estimated to be $1.3 \times$ $10^{-3} \mathrm{~cm}^{2} \mathrm{~V}^{-1} \mathrm{~s}^{-1}$. This relatively low field mobility value may be ascribed to the limited solubility of $\mathbf{2}$, which hampered the formation of an entirely contiguous thin film of pentacene between the source and the drain.

The photochemical conversions of $\mathbf{1}$ and $\mathbf{2}$ to pentacene films for OTFT devices were examined in a separate experiment. A solution containing an equal molar ratio of $\mathbf{1}$ and $\mathbf{2}$ was spin-coated into a film, which was then irradiated with UV light in a drybox at ambient temperature to transform the precursors into pentacene. The resulting device exhibited a field-effect mobility of $2.4 \times 10^{-3} \mathrm{~cm}^{2} \mathrm{~V}^{-1} \mathrm{~s}^{-1}$ and an on/off current ratio of $3.96 \times 10^{4}$ (Figure $4 \mathrm{c}, \mathrm{d}$ ), which indeed was better than that with thermally generated pentacene. This is the first report on the photogeneration of pentacene that was used successfully on OTFT devices. (a)

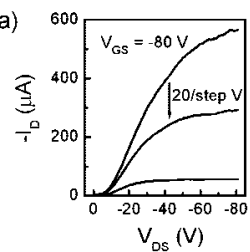

(c)

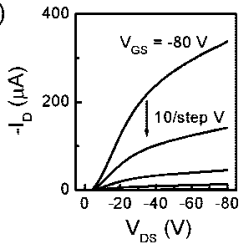

(b)

(d)

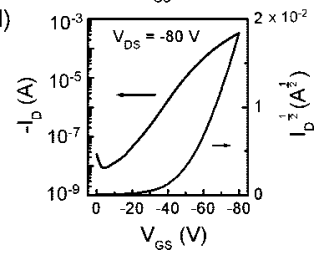

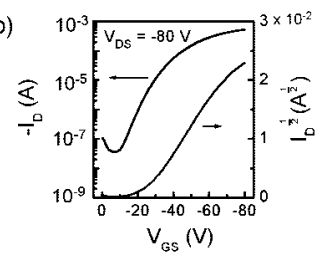

Figure 4. Plots $\mathrm{a}$ and $\mathrm{b}$ are for an OTFT device made of thermal generated pentacene: (a) plot of drain current $I_{\mathrm{D}}$ versus drain-source voltage $V_{\mathrm{DS}}$ at various gate voltages $V_{\mathrm{GS}}$; (b) plot of $\log \left(I_{\mathrm{D}}\right)$ vs $V_{\mathrm{GS}}$ for $V_{\mathrm{DS}}=-80 \mathrm{~V}$, and $I_{\mathrm{D}}{ }^{1 / 2}$ vs $V_{\mathrm{GS}}$ in the saturation region. Plots $\mathrm{c}$ and $\mathrm{d}$ are the corresponding ones for a device made of photogenerated pentacene.

In summary, a new soluble pentacene precursor $\mathbf{2}$ with a nonsymmetrical molecular structure was synthesized in $40 \%$ yield from the cycloaddition of a furan derivative 3 and a benzonorbornadiene 4 . Compound 2 expelled a unit of $\mathrm{CO}$ upon heating at $128^{\circ} \mathrm{C}$ or by UV irradiation (e.g., $366 \mathrm{~nm}$ ) to produce pentacene in high yield. A thin film of pentacene can be prepared by spin-coating the precursors, followed by $\mathrm{CO}$ expulsion. The devices thus prepared displayed effective FET characteristics. Although the solubility of precursors can be doubled by mixing $\mathbf{1}$ and $\mathbf{2}$ together, an entirely contiguous thin film of pentacene is still hard to obtain. Work focusing on improvements of film morphology and the performance of OTFT devices is currently in progress.

Acknowledgment. Financial support from the National Science Council (Taiwan) and a theme project of Academia Sinica is gratefully acknowledged.

Supporting Information Available: Synthetic experimental and characterization data for compounds $\mathbf{2}$ and 5-10. This material is available free of charge via the Internet at http://pubs.acs.org.

OL8010419 